\title{
Co-Activation of TGF $\beta$ and Wnt Signalling Pathways Abrogates EMT in Ovarian Cancer Cells
}

\author{
Tulika Mitra ${ }^{a}$ Sib Sankar Roya,b \\ aCell Biology and Physiology Division, CSIR-Indian Institute of Chemical Biology, 4 Raja S. C. Mullick \\ Road, Kolkata, ${ }^{b}$ Academy of Scientific and Innovative Research, CSIR- Indian Institute of Chemical \\ Biology Campus, 4 Raja S. C. Mullick Road, Kolkata, India
}

\section{Key Words}

$\mathrm{EMT} \cdot \mathrm{TGF} \beta \cdot \mathrm{Wnt} \cdot \beta$-catenin

\begin{abstract}
Background/Aims: The aggressive property of ovarian cancer (OC) in terms of epithelialmesenchymal transition (EMT), proliferation and metastasis are of major concern. Different growth factors including TGF $\beta$ are associated with regulating these molecular events but the underlying mechanisms remain unclear. The aim of this report is to decipher the regulation of EMT by co-activation of TGF $\beta$ and Wnt signalling cascades in gaining malignancy. Methods: The expression of the different components of signalling events were analyzed by QPCR, Western blot, Immunofluorescence microscopy and flow cytometry. $\beta$-catenin promoter activity was checked by luciferase assay. Results: We observed reduced EMT in ovarian cancer cells upon co-activation with TGF $\beta 1$ and $\mathrm{LiCl}$ as shown by the expressions of epithelial/ mesenchymal markers and the EMT promoting factor, Snail1, accompanied by decrease in the invasion and migration of the cells compared to individual pathway activation. A detailed study of the mechanism suggested reduction in the $\beta$-catenin and p-GSK3b (Ser 9) levels to be the driving cause of this phenomenon, which was reversed upon co-activation with higher concentrations of $\mathrm{LiCl}$. Conclusions: Therefore, tumourigenesis might be affected by the concentration of ligand/ growth factors for the respective signalling pathways activated in the tumour microenvironment and interaction between them might alter tumourigenesis.
\end{abstract}

(C) 2017 The Author(s)

Published by S. Karger AG, Basel

\section{Introduction}

Epithelial Ovarian Cancer (EOC) is the fourth leading cause of gynaecological malignancy around the world [1]. Being asymptomatic in the earlier stages, the detection, mostly in FIGO Stage III, reveals its metastasis to various parts of the body, resulting in poor prognosis [2].

Sib Sankar Roy

KARGER
Cell Biology and Physiology Division, CSIR-Indian Institute of Chemical Biology, 4 Raja S. C. Mullick Road, Kolkata 700032 (India)

Tel.+ 91-33-2499-5858, Fax + 91-33-2473-5197, E-Mail sibsankar@iicb.res.in 


\section{Cellular Physiology Cell Physiol Biochem 2017;41:1336-1345

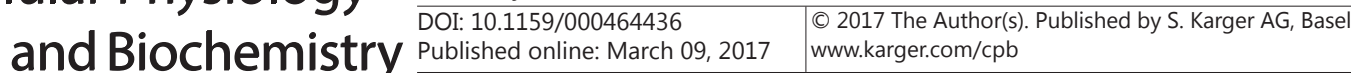 \\ Mitra/Roy: TGF $\beta$ and Wnt Together Attenuates EMT}

EOCs are highly aggressive in nature and make up 70\% of all ovarian cancers. Uncontrolled hyper-activation of different growth factor signalling cascades are evident in supporting cancer growth and metastasis [3-10]. Extremely well regulated signalling network in the form of cross talks between different growth factor signalling pathways are common in the developing organs of the embryo $[11,12]$. The same network exists in cancer [13], but it is not well regulated and brings about malignancy in the same.

TGF $\beta$ pathway is one of the major pathways involved in development, responsible for regulating embryogenesis, maintaining adult tissue homeostasis, regulating proliferation, differentiation, apoptosis, and migration in different cell types. It is a homodimeric cytokine which functions by binding to cell surface receptors to activate the Regulatory Smads (Smad 2 or 3, depending on the cell type) proteins, which, with the help of the Co-Smad (Smad 4), translocate to the nucleus and act as cofactors for the transcription of target genes [14,15]. Hyperactivation of the TGF $\beta$ pathway has been reported in many cancer types [10]. Again, it plays a dual role-in the early stages of tumour development, it suppresses tumour growth and induces apoptosis, but in the later stages, it mediates tumour progression by inducing Epithelial-Mesenchymal Transition (EMT), migration and invasion [14].

TGF $\beta 1$, with the help of different mediators $[16,17]$, is a known inducer of EMT, a dedifferentiating process in which the epithelial cells lose their cobblestone-shaped morphology and gains spindle-shaped mesenchymal morphology with formation of actin stress fibres, reduced cell-cell junctions, polarization disruption and increased cellular motility $[18,19]$. Several other signalling pathways are also known to induce EMT $[9,20,21]$, Wnt signalling being one of them. Wnt functions by binding to the cell surface receptor Frizzled, which, in turn, inactivates Glycogen Synthase Kinase $3 \beta$ (GSK3 $\beta$ ), leading to stabilization of $\beta$-catenin [22], which translocates to the nucleus and upregulates the transcription of its target genes, many of which induce EMT. Chemicals like Lithium chloride inhibits GSK3 $\beta$ and stabilizes $\beta$-catenin $[23,24]$, thus activating Wnt signalling pathway.

In the tumour microenvironment, several different growth factors, cytokines and oncometabolites are present, which affect cancer progression through EMT, invasion and migration individually or in unison $[13,25,26]$. Therefore, it is important to investigate the co-activation of two different signalling pathways to check the fate of cancer cells in terms of progression. Previous reports suggest that Wnt and TGF $\beta$ promote EMT [27-29]. Considering background references regarding Wnt and TGF $\beta$ signalling cascades in EMT and ovarian cancer [28-30], we wanted to study the effect of this co-activation in these processes to mimick a part of the signalling cascade functioning in the tumour microenvironment. In this report, we have shown the effect of the functioning of Wnt and TGF $\beta$ in unison in abrogating EMT.

\section{Materials and Methods}

\section{Cell culture and treatments}

Human ovarian adenocarcinoma cells SK-OV3 and OAW-42 (ATCC and Sigma respectively) were cultured under standard conditions in McCoy's 5A (Sigma) and DMEM (Gibco ${ }^{\mathrm{TM}}$, Invitrogen, USA) respectively; both supplemented with $10 \%$ fetal bovine serum (FBS), $100 \mathrm{U} / \mathrm{ml}$ Penicillin G, $100 \mu \mathrm{g} / \mathrm{ml}$ Streptomycin $\left(\mathrm{Gibco}^{\mathrm{TM}}\right)$. Cells were serum starved for $6 \mathrm{hrs}$ prior to treatments with $10 \mathrm{ng} / \mathrm{ml}$ Human recombinant TGF $\beta 1$ (rh TGF $\beta 1$; Calbiochem, San Diego) to activate the TGF $\beta$ signalling pathway and 25 $\mathrm{mM}$ lithium chloride (LiCl) (Sigma- Aldrich; St Louis, USA) to activate the canonical Wnt signalling pathway or vehicles (0.1\% BSA in 1X PBS). Dual treatment involved treating the cells with both TGF 1 and LiCl simultaneously. TGF $\beta$ receptor inhibitor (RI; Calbiochem) was used to block the TGF $\beta$ signalling pathway and Dickkopf1 (DKK1; R\&D Biosystems) was used as an inhibitor for the Wnt signaling pathway.

Transient transfection and luciferase assay

For reporter assay, $5 \times 10^{4}$ cells seeded on 12 -well culture plates. Cells were transfected with the luciferase reporters SuperTOPFlash-TCF4 (under the control of 8 TCF4 consensus sites; plasmid 12456, 


\section{Cellular Physiology Cell Physiol Biochem 2017;41:1336-1345

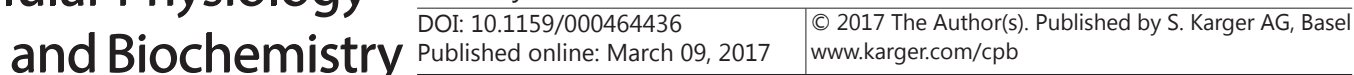 Mitra/Roy: TGF $\beta$ and Wnt Together Attenuates EMT}

Table-1. List of primers

\begin{tabular}{lllll}
\hline Gene & Accession ID & Forward Primer & Reverse Primer & Tm \\
\hline 18 rRNA & 100008588 & GATTCCGTGGGTGGTGGTGC & AAGAAGTTGGGGGACGCCGA & 60 \\
CDH1 & 999 & GTCACTGACACCAACGATAATCCT & TTTCAGTGTGGTGATTACGACGTTA & 60 \\
CDH2 & 1000 & CCATCAAGCCTGTGGGAATC & GCAGATCGGACCGGATACTG & 60 \\
CLDN7 & 65132 & GTGGCAGATGAGCTCCTATGC & CATCCACAGCCCCTTGTACA & 60 \\
SNAI1 & 6615 & TCGGAAGCCTAACTACAGCGA & AGATGAGCATTGGCAGCGAG & 60 \\
VIM & 7431 & ACACCCTGCAATCTTTCAGACA & GATTCCACTTTGCGTTCAAGGT & 60 \\
\hline
\end{tabular}

Addgene) or SuperFOPFlash (with mutant TCF4 reporter sites; plasmid 12457, Addgene). Transfection and dual luciferase assay was carried out in the 96 well Glomax luminometer (Promega) as previously described [29].

RNA isolation and Quantitative Real-time PCR ( $q$-PCR)

Total RNA was isolated from cell-lines using TRI reagent (Sigma- Aldrich) following standard protocol and were processed and analyzed as previously described [31]. The list of primers used with their respective sequences and $\mathrm{Tm}$ are listed in Table 1.

\section{Western blot analysis}

Cell lysis and protein extraction were performed as described previously following 24 hours of treatment [32] and subjected to immunoblotting with primary antibodies (1:2000)- $\beta$-catenin, GSK3 $\beta$, Axin, Claudin 7, Snail1, GAPDH, $\alpha$-tubulin (Santa Cruz Biotechnology, Carlsbad, USA), Vimentin, N-cadherin, p-GSK3 $\beta$ (Ser 9), GSK3 $\beta$, Histone H3 (Cell Signalling Technologies, USA). Secondary antibodies used were tagged with Horse Radish Peroxidase (HRP) and chemiluminiscence was detected on reaction with ECL detection reagent (Bio-Rad, Hercules, CA, USA) in a chemidetector (UVP). The images were quantified using the Image J software.

\section{In vitro Invasion Assay}

In vitro cell invasion was studied using Matrigel invasion chamber (BD Biosciences, Bedford, USA) following the manufacturer's guideline. In brief, $2.5 \times 10^{5}$ cells were seeded in the inserts of the Matrigel and treated with TGF 1 , $\mathrm{LiCl}$ or both. The invasion chamber was incubated at $37^{\circ} \mathrm{C}$ in $5 \% \mathrm{CO} 2$ atmosphere for $22 \mathrm{~h}$ and Matrigel invasion assay was performed. The values obtained were calculated using the number of invaded cells from three filters.

\section{Wound Healing Assay}

Ovarian cancer cells at high confluency were serum starved and wounding was performed by scraping through the cell monolayer with a $200 \mu \mathrm{l}$ pipette tip. Medium and non-adherent cells were removed, and cells were washed twice with PBS, and fresh serum-free medium with TGF $\beta 1$, LiCl or both was added. Cells were permitted to migrate into the area of clearing for 24-72 hrs. Wound closure was monitored by visual examination under microscope and the rate of migration was quantified by the ImageJ software.

\section{Immunofluorescence microscopy}

Immunofluorescence was carried out as described previously [30] using the antibodies Claudin 7, Vimentin, Snail and $\beta$-catenin.

\section{Flow cytometric intracellular antigen staining}

Treated cells were fixed in ice-cold $70 \%$ ethanol followed by incubation at $4^{\circ} \mathrm{C}$ for $30 \mathrm{~min}$. and centrifugation at approximately $800 \mathrm{~g}$ for $5 \mathrm{~min}$. They were then permeabilized with $0.25 \%$ Triton-X, followed by incubation with 1:200 dilution primary $\mathrm{Ab}$ and 1:600 dilution secondary Ab conjugated to a fluorophore for $30 \mathrm{~min}$ and analyzed by flow cytometry. Analysis was carried out in the instrument LSR Fortessa (BD) with the help of FACS Diva software.

\section{Statistical analysis}

All data are expressed as mean \pm S.E.M. represented by error bars. The experiments were repeated at least three times in duplicate. 


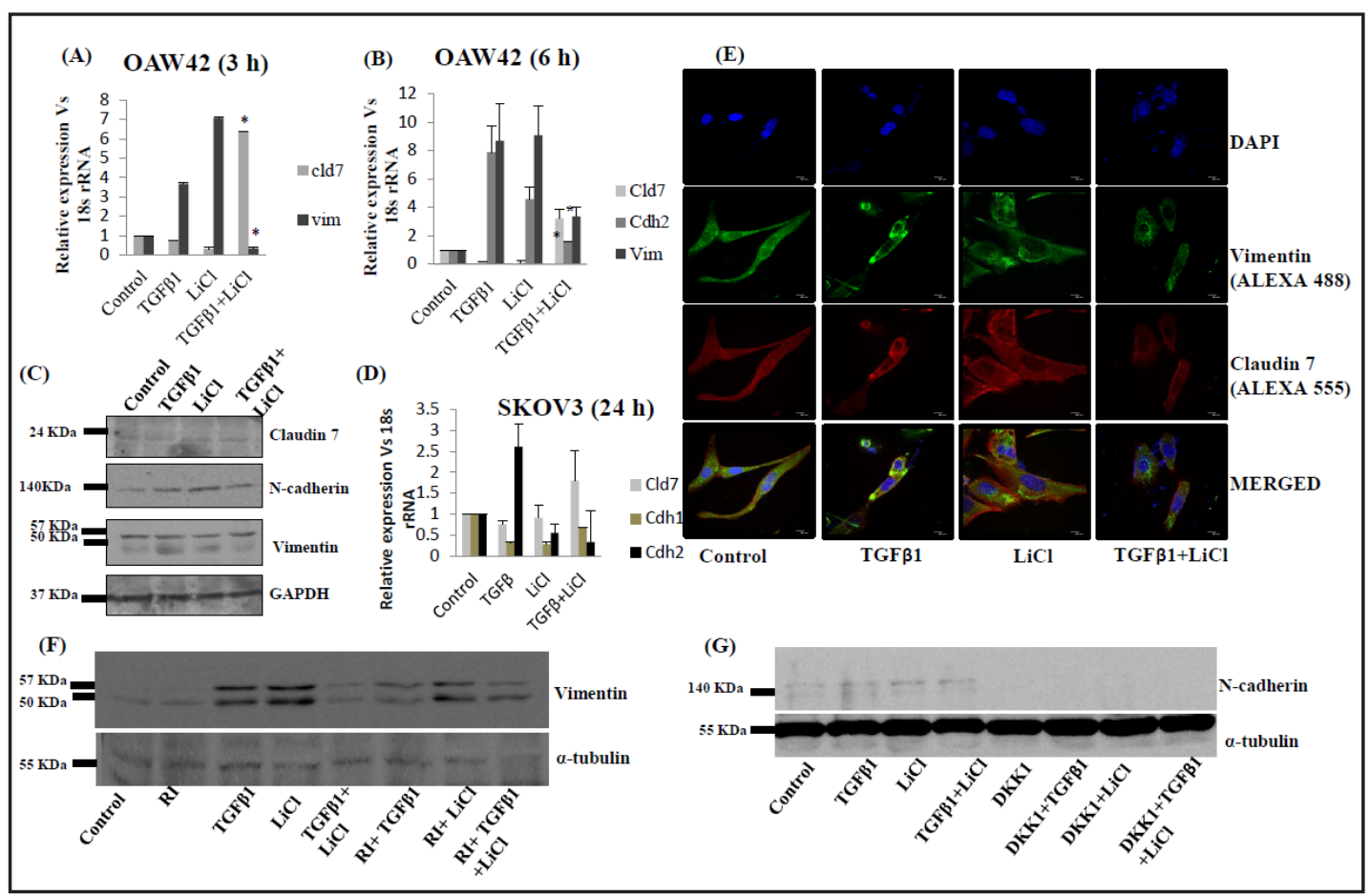

Fig. 1. EMT as measured by epithelial markers Claudin 7 (Cld 7 ) and E-Cadherin (Cdh 1) and mesenchymal markers $\mathrm{N}$-Cadherin (Cdh 2) and Vimentin (Vim), ${ }^{*} \mathrm{p}<0.005$ at $3 \mathrm{~h}$ (A), 6h (B) and Western blot analysis supporting the same results at translational level (C) in individual treatments versus dual treatment with TGF $\beta 1$ and $25 \mathrm{mM} \mathrm{LiCl.} \mathrm{GAPDH}$ was used as a loading control. The qPCR data showing the expression of the EMT associated genes in SKOV3 cells (D). Immunofluorescence data showing the changes in expression of the epithelial marker CLAUDIN 7 (red) and the mesenchymal marker VIMENTIN (green) and morphological changes in co-activated cells compared to individual ones (E). Western blot showing the expression of the mesenchymal markers upon inhibition of the TGF $\beta$ pathway by the receptor inhibitor (RI) (F) and the Wnt pathway blocker DKK1 (G).

\section{Results}

EMT was reduced when the ovarian cancer cells were co-activated with TGF 31 and LiCl

The status of EMT in TGF $1 / \mathrm{LiCl}$ co-treated cells (OAW42) was measured by gene expression profile of different markers and was compared with that of individual treatments at different time points. Though numerous EMT-associated genes were analyzed, only few showed expression in our cell of interest and their time of expression varied in many cases. Upregulation of mesenchymal markers (Cdh2 and Vim) with downregulation of the epithelial markers (Cdh1 and Cld7) were observed in individual treatments, whereas, in dual treatment, EMT was abrogated as shown by q-PCR (Fig. 1A-B), Western immunoblot analysis (Fig. 1C) and immunofluorescence microscopy (Fig. 1E) in the downregulation of mesenchymal markers (Vimentin, N-cadherin) and upregulation of epithelial markers (Claudin 7, E-cadherin). Similar results were obtained in qPCR in another cell line SKOV3 (Fig. 1D). Inhibition of the TGF $\beta$ pathway by the receptor inhibitor (RI) led to downregulation of the mesenchymal marker Vimentin, but further treatment with each ligand led to restoration of the same marker (Fig. 1F). Similarly, downregulation of the Wnt signalling pathway by prior treatment with DKK1 led to downregulation of the mesenchymal marker N-cadherin (Fig. 1G). $\alpha$-tubulin was measured to ensure uniform loading.

The EMT promoting transcription factor, Snail is downregulated upon co-activation

When the TGF $\beta 1$ and Wnt signalling pathways are co-activated, the expression of the EMT-inducer Snail1 was downregulated compared to that in the activation of individual

\section{KARGER}




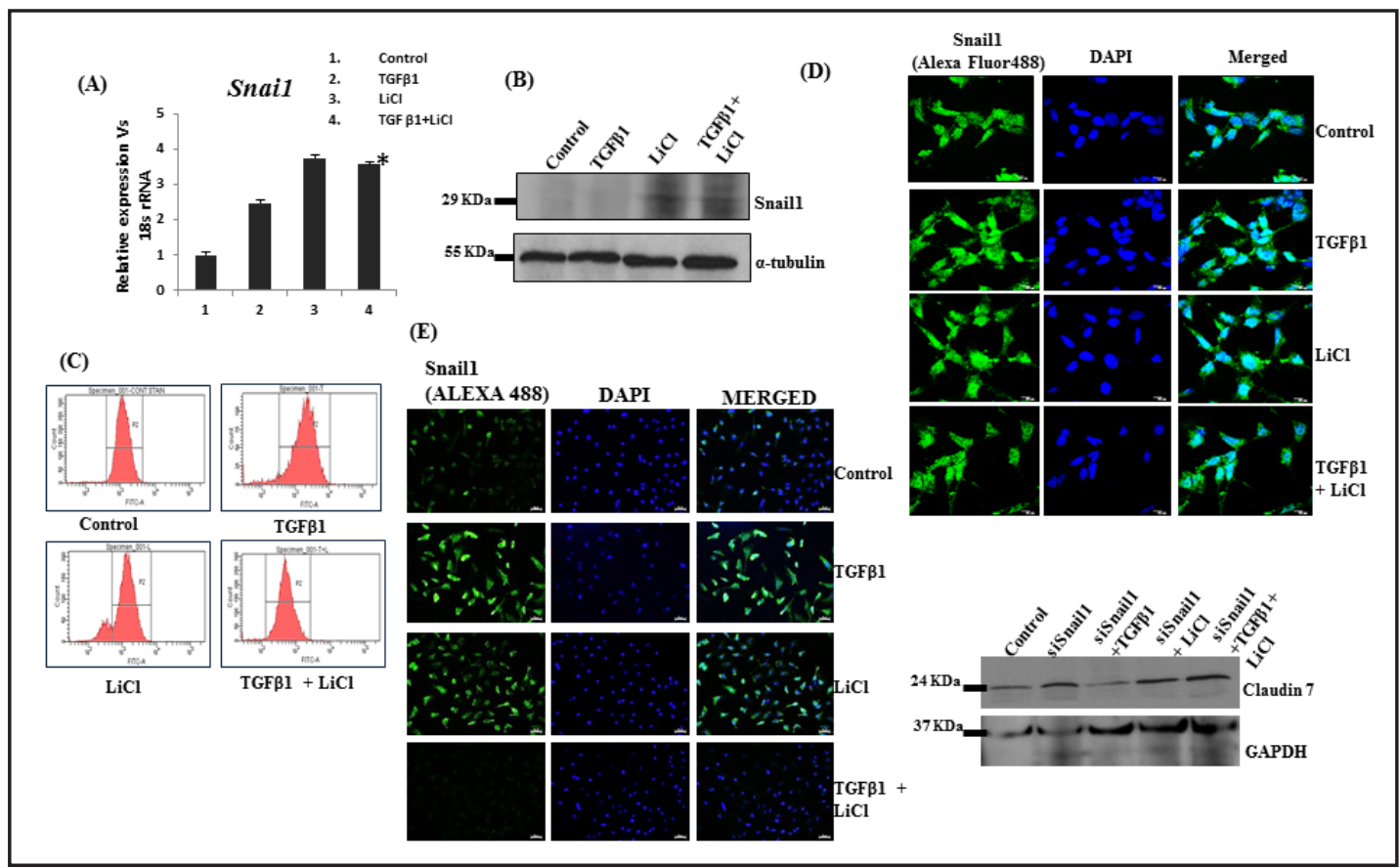

Fig. 2. Expression of the EMT inducing transcription factor Snail1 as studied by (A) q-PCR, *p<0.005 (B) Western blot and (C) flow cytometry. In the Western blot analysis, $\alpha$-tubulin was used as a loading control. All the studies corroborated the fact that Snail1 expression decreased in the co-activated cells compared to the individually activated cells. (D) Nuclear translocation studies of SNAIL1 in OAW42 cells showed enhanced nuclear localisation of SNAIL1 in cells activated with TGF $\beta$ or LiCl, which decreased upon coactivation. (E) Immunofluorescence studies showing changes in SNAIL1 expression in co-activated cells compared to the individual activation of each pathway in SKOV3 cells. (F) Western blot analysis showing the upregulation of Claudin 7 expression upon siRNA mediated knockdown of Snai1.

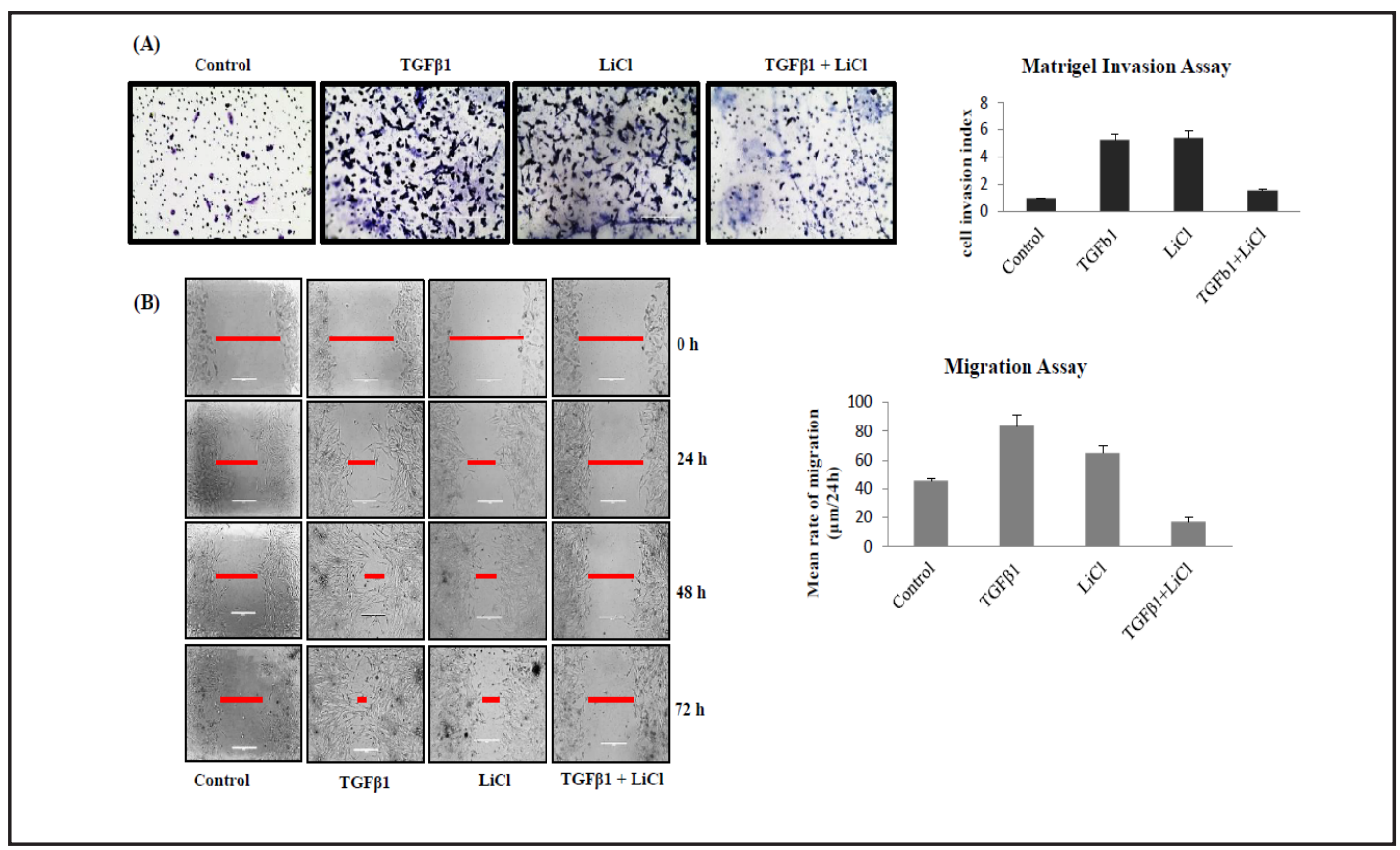

Fig. 3. (A) Matrigel invasion assay and (B) Scratch wound assay in untreated (control) cells compared to individual treatments with TGF $\beta 1$ or LiCl or both. The bar diagrams represent cell invasion index $\left({ }^{*} \mathrm{p}<0.005\right)$ in case of invasion and the rate of migration $(\mu \mathrm{m} / 24 \mathrm{~h})$ for the scratch wound assay. 


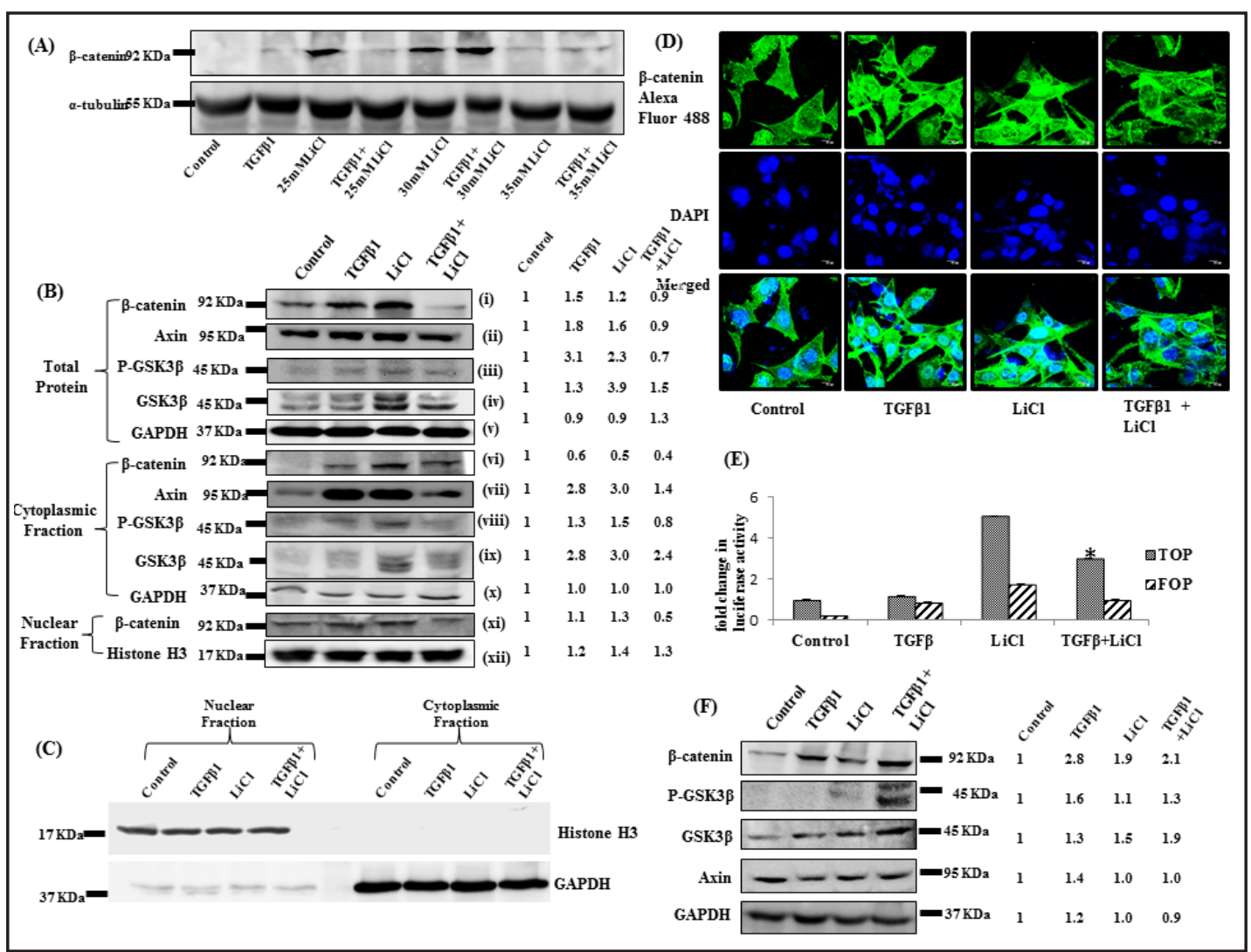

Fig. 4. (A) Western blot analysis showing $\beta$-catenin protein level upon activation of the Wnt signalling pathway by $25 \mathrm{mM}, 30 \mathrm{mM}$ and $35 \mathrm{mM}$ of $\mathrm{LiCl}$ with or without TGF $\beta 1$. (B) Study of the downstream component of Wnt signalling pathways from whole cell lysates as well as cytoplasmic and nuclear fractions of cells co-activated with TGF $\beta$ and $\mathrm{LiCl}$ compared to cells treated only with TGF $\beta$ or LiCl or vehicle. The primary downstream component $\beta$-catenin (i) from the whole cell lysate. This was followed by studying the levels of Axin (ii), p-GSK3 $\beta$ (Ser 9) (iii), total GSK3 $\beta$ (iv), GAPDH (v) being used as a loading control. Protein isolated from the cells under similar treatment conditions were separated into cytoplasmic and nuclear fractions. Each fraction was analyzed for the same set of proteins. $\beta$-catenin from both cytoplasmic (vi) and nuclear (xi) fractions were compared against the loading controls GAPDH (x) and Histone H3 (xii) respectively. Axin (vii), p-GSK3 $\beta$ (Ser9) (viii) and total (ix) bands were observed in cytoplasmic fractions only. (C) Western blot analysis from nuclear and cytoplasmic fractions showing the expression of the nuclear marker Histone H3 and the cytoplasmic marker GAPDH. (D) Nuclear translocation of $\beta$-catenin was also studied by immunofluorescence microscopy in co-activated cells in comparison to cells with TGF $\beta$ or Wnt signalling activation. (E) Promoter activity of $\beta$-catenin determined by dual luciferase assay in the co-activated cells compared to LiCl activation ${ }^{*} \mathrm{p}<0.005$. (F) Data showing protein levels of $\beta$-catenin (i), p-GSK3 $\beta$ (Ser9) (ii), total GSK3 $\beta$ (iii) and Axin levels (iv) in case of $35 \mathrm{mM} \mathrm{LiCl}$ treatment with or without TGF $\beta 1$ compared to vehicle treatment. The charts represent the intensities of each band in R.A.U.

pathway, as measured by q-PCR (Fig. 2A), Western blot (Fig. 2B) and flow cytometry (Fig. 2C) analyzes. $\alpha$-tubulin was used as a loading control for the immunoblot. This was further supported by immunofluorescence microscopy, where Snail1 showed reduced nuclear translocation (Fig. 2D) in OAW42 cells. Immunofluorescence microscopic studies showed reduced expression of Snail1 in SKOV3 cells in co-activation compared to individual activation (Fig. 2E) of each pathway. siRNA mediated knockdown of Snail1 in the OAW42 cells led to gain of the epithelial characteristic, as observed by the expression of Claudin 7 by Western blot analysis, GAPDH being used as a loading control (Fig. 2F). 


\section{Cellular Physiology Cell Physiol Biochem 2017;41:1336-1345 \\ \begin{tabular}{l|l} 
and Biochemistry Published onlıne: March 09, 2017 & $\begin{array}{l}\text { (c) } 2017 \text { The Author(s). Published by S. Karger AG, Basel } \\
\text { www.karger.com/cpb }\end{array}$
\end{tabular} \\ Mitra/Roy: TGF $\beta$ and Wnt Together Attenuates EMT}

Effect of the co-activation on invasion and migration of the ovarian cancer cells

Matrigel invasion assay (Fig. 3A) showed a decrease in the cell invasion index upon dual treatment with TGF $\beta 1$ and LiCl compared to individual treatment. The bar diagram shows data signifying cell invasion index with respective treatment. Migration studies conducted by scratch wound assay (Fig. 3B) showed complete or near complete wound closure in individual pathway activation, which was attenuated when both the pathways were activated. The bar diagram signifies the rate of migration $(\mu \mathrm{m} / 24 \mathrm{~h})$ in case of singular or co-activation.

\section{$\beta$-catenin levels determine the mechanism of EMT attenuation}

Expression of $\beta$-catenin observed in Western blot analysis by activation of the Wnt signalling pathway by different doses of $\mathrm{LiCl}(25 \mathrm{mM}, 30 \mathrm{mM}, 35 \mathrm{mM})$ with or without simultaneous induction of the TGF $\beta$ signalling pathway. $\alpha$-tubulin was used as a loading control (Fig. 4A). Comparison of dual treatment with individual treatments showed reduced $\beta$-catenin expression (total, cytoplasmic and nuclear, Fig. 4Bi, vi, xi respectively), as shown by Western blot analysis. Total and cytoplasmic axin levels were decreased in dual treatment, but was considerably increased in individual treatment (Fig. 4Bii, vii). Reduced $\beta$-catenin levels were accompanied by reduced p-GSK3 $\beta$ (Ser9) levels (Fig. 4Biii and viii), in the dual treatment compared to LiCl treatment alone. Total GSK3 $\beta$ was also measured (Fig. 4Biv, ix). GAPDH was used as a loading control for total (Fig. 4Bv) and cytoplasmic fractions (4Bx), whereas, Histone $\mathrm{H} 3$ was used as a loading control for nuclear fraction (Fig. 4Bxii). Axin, p-GSK3 $\beta$ (Ser9) and GSK3 $\beta$ were absent in nuclear fractions. Western immunoblot analysis to show the absence of cytoplasmic fraction contamination in nuclear fraction and vice versa (Fig. 4C), where GAPDH is a cytoplasmic marker and Histone H3 is the nuclear counterpart. Immunofluorescence microscopy (Fig. 4D) showed hindered nuclear localisation of $\beta$-catenin in the co-activated cells than that with individual activation. The luciferase assay (Fig. 4E) suggested decreased $\beta$-catenin promoter activity in the co-activated cells compared to the LiCl-treated cells. To ascertain the mechanism of action behind the reduction in $\beta$-catenin level, cells treated with higher concentration of $\mathrm{LiCl}(35 \mathrm{mM})$ with or without TGF $\beta 1$ was analyzed, which showed higher $\beta$-catenin levels in dual treatment. This change in expression was concurrent with changes in the levels of p-GSK3 $\beta$ (Ser 9) (Fig. 4F). The panel beside the Western blot images represent the respective band intensities (R.A.U.).

\section{Discussion}

Signalling aberrations in different cancer types are common and contribute majorly to tumourigenesis. TGF $\beta$ and Wnt, the master regulators of embryogenesis, are also known to induce the same functions [29, 33], being upregulated in ovarian cancer $[16,17,32]$. Crosstalk between the two pathways is reported during developmental stages $[11,12,27]$, however, in cancer, though their interaction has been reported [13], the exact effect on cancer progression is still not known. In this study, we aim to uncover this effect on ovarian cancer progression. Each pathway when separately activated, increased EMT, migration and invasion, whereas a dual activation reduced this effect. However, EMT and migration and invasion are well related [34, 35]. Cancer cells undergoing metastasis frequently show the phenomenon of EMT. We observed the mesenchymal markers $\mathrm{N}$-cadherin and Vimentin to be upregulated, suggesting EMT induction upon individual treatment with each factor. However, the co-activation of the TGF $\beta$ and Wnt signalling pathways failed to demonstrate this change. An observation opposing the marker levels in EMT induction led us to believe decreased EMT upon dual activation.

EMT is brought about by the transcriptional promoters like Snail1/2, Zeb1/2 and Twist [34]. Snail1 is the earliest inducer of EMT reported [36], which regulates the expressions of the genes responsible for promoting or inhibiting EMT [36, 37]. Reduced expression of SNAIL1 in co-activation of TGF $\beta$ and Wnt signalling suggested inhibition of EMT in this condition. Snail1-induced reduction of E-cadherin increases and stabilizes $\beta$-catenin, 


\section{Cellular Physiology Cell Physiol Biochem 2017;41:1336-1345 \\ \begin{tabular}{ll|l} 
DOI: 10.1159/000464436 & Ond Biochemistry Published online: MVarch 09, 2017 & $\begin{array}{l}\text { 2 2017 The Author(s). Published by S. Karger AG, Basel } \\
\text { www.karger.com/cpb }\end{array}$
\end{tabular} \\ Mitra/Roy: TGF $\beta$ and Wnt Together Attenuates EMT}

which then translocates to the nucleus, upregulating its target genes. Reduced Snail1, in conjunction with reduced $\beta$-catenin marked the EMT inhibition. Now, $\beta$-catenin is a key downstream component of the Wnt signalling pathway, where its stabilization is directly proportional to GSK3 $\beta$ phosphorylation at Ser9. To ascertain this fact, the experiments conducted corroborated the results with reduced p-GSK3 $\beta$ (Ser 9) levels in dual pathway activation compared to only $\mathrm{LiCl}$ treatment. The reduced axin levels in dual treatment suggested the less availability of the scaffold protein in comparison to individual treatment. Even the luciferase assay proved the reduced $\beta$-catenin promoter activity in co-activated cells. However, this effect was seen only at a particular range of $\mathrm{LiCl}$ concentration $(25 \mathrm{mM})$. At higher concentrations (viz. 35mM), p-GSK3 $\beta$ (Ser9) levels were increased that causes $\beta$-catenin level to increase, thus promoting metastasis. This sheds light on how some tumours remain benign, while others go on to become malignant.

Our study is not the first to report an event of this kind. Previous experiments in human bronchial fibroblasts (HBFs) from non-asthmatic patients showed that the differentiation from fibroblast to myofibroblast was enhanced upon lithium administration to the TGF $\beta$ treated cells. However, this 'differentiation' process was inhibited in HBFs isolated from asthmatic patients, suggesting that the TGF $\beta$-treated HBFs show opposing response to $\mathrm{LiCl}$ treatment indicating the inconsistent outcome of the interaction between TGF $\beta$ and Wnt signalling pathways [38]. Another study carried out in keloids and hypertrophic scars reported that TGF $\beta$ could activate and then inhibit the $\mathrm{Wnt} / \beta$-catenin pathway in pathological scar formation. They also reported decrease in $\beta$-catenin levels under the influence of different TGF $\beta$ concentrations, suggesting that both synergism as well as antagonism exist in the interaction of these pathways [39]. Therefore, $\mathrm{LiCl}$ treatment and activation of Wnt signalling pathway could interfere with the TGF $\beta$-mediated action in cancer and non-cancer cell types. In the present study, we got a similar observation. At present, the exact mechanism of this inhibitory activity of TGF $\beta$ as well as Wnt signalling pathways, when they are coactivated, may not be explained fully. However, it is possible that alteration or variation of concentrations or stoichiometry of different factors including growth factors in tumour microenvironment might significantly contribute in dysregulating the signalling events in cancer cells $[39,40]$. Among many evidences, the present study is a very prominent one to show the cross-talk between two major pathways that might play differential roles in ovarian cancer progression, subject to their stoichiometry in tumour microenvironment (TME).

In conclusion, though several studies report on the interactions between the TGF $\beta$ and the Wnt signalling pathways, their cross-talk has been shown in this investigation to regulate oncogenic abilities of the ovarian cancer cells. It is possible that the relative concentration of ligands and/or inducers of different signalling pathways in the tumour microenvironment might act as deciding factors on whether or how these signalling events continue or culminate to regulate cancer progression. From our data it might be speculated that the differential expression of $\beta$-catenin in different concentrations of $\mathrm{LiCl}$ in conjunction with TGF $\beta$ might explain how a non-metastatic benign tumour gains metastatic potential to enhance malignancy. This claim can further be strengthened by measuring the serum TGF $\beta$ and $\beta$-catenin levels in patient cohorts ranging from normal to benign ovarian tumours to highly malignant cancers. Therefore, the concentration of ligands as well as the inducers of different signalling pathways present in the TME might possibly decide the fate of their cross-talks. At certain concentrations it might inhibit EMT/invasion and at others, it can favour these events. This background information may be of importance while considering the therapeutic aspects modulating these signalling events to reduce ovarian cancer progression.

\section{Acknowledgements}

We thankfully acknowledge Council of Scientific and Industrial Research (CSIR project nos. 0101 and 0206), Govt. of India for funding. TM is the recipient of CSIR fellowship 


\section{Cellular Physiology Cell Physiol Biochem 2017;41:1336-1345 \begin{tabular}{ll|l} 
DOI: 10.1159/000464436 & and Biochemistry Published online:1Varch 09, 2017 & $\begin{array}{l}\text { O 2017 The Author(s). Published by S. Karger AG, Basel } \\
\text { www.karger.com/cpb }\end{array}$
\end{tabular} \\ Mitra/Roy: TGF $\beta$ and Wnt Together Attenuates EMT}

(No. 31/039(0332)/2012-EMR-I). Parash Prasad and Prabir Kr. Dey of our laboratory are gratefully acknowledged for their technical assistance. Diptodeep Sarkar, Suraiya Saleem and Anushila Gangopadhyay are kindly acknowledged for their assistance with fluorescence microscopy and flow cytometry respectively. The other members of SSR laboratory are acknowledged for their kind co-operation.

\section{Disclosure Statement}

The authors declare no conflict of intrest.

\section{References}

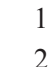

$>2$

$>3$

Jayson GC, Kohn EC, Kitchener HC, Ledermann JA: Ovarian cancer. Lancet 2014;384:1376-1388. Jacobs I, Oram D, Fairbanks J, Turner J, Frost C, Grudzinskas JG: A risk of malignancy index incorporating CA 125 , ultrasound and menopausal status for the accurate preoperative diagnosis of ovarian cancer. $\mathrm{Br} \mathrm{J}$ Obstet Gynaecol 1990;97:922-929.

Witsch E, Sela M, Yarden Y: Roles for Growth Factors in Cancer Progression. Physiology (Bethesda) 2010;25:85-101.

Song N, Liu H, Ma X, Zhang S: Placental Growth Factor Promotes Metastases of Ovarian Cancer Through MiR-543-Regulated MMP7. Cell Physiol Biochem 2015;37:1104-1112.

Zhanga W, Zhang T, Lou Y, Yan B, Cui S, Jiang L, Han B: Placental Growth Factor Promotes Metastases of Non-Small Cell Lung Cancer Through MMP9. Cell Physiol Biochem 2015;37:1210-1218.

Song N, Liu H, Ma X, Zhang S: Placental Growth Factor Promotes Ovarian Cancer Cell Invasion via ZEB2. Cell Physiol Biochem 2016;38:351-358.

Li Y, Li Y, Zhang J, Zheng C, Zhu H, Yu H, L Fan L: Circulating Insulin-Like Growth Factor-1 Level and Ovarian Cancer Risk. Cell Physiol Biochem 2016;38:589-597.

Ying X, Sun Y, He P: Bone Morphogenetic Protein-7 Inhibits EMT-Associated Genes in Breast Cancer. Cell Physiol Biochem 2015;37:1271-1278.

Ogunwobi O0, Liu C: Hepatocyte growth factor upregulation promotes carcinogenesis and epithelialmesenchymal transition in hepatocellular carcinoma via Akt and COX-2 pathways. Clin Exp Metastasis 2011;28:721-731.

Massagué J: TGFß in Cancer. Cell 2008;134:215-230.

Nishita M, Hashimoto MK, Ogata S, Laurent MN, Ueno N, Shibuya H, Cho KW: Interaction between Wnt and TGF $\beta$ signalling pathways during formation of Spemann's organizer. Nature 2000;403:781-785.

Warner DR, Greene RM, Pisano MM: Cross-talk between the TGF $\beta$ and Wnt signaling pathways in murine embryonic maxillary mesenchymal cells. FEBS Lett 2005;579:3539-3546.

Katoh M. Networking of WNT, FGF, Notch, BMP, and Hedgehog Signaling Pathways during Carcinogenesis. Stem Cell Rev 2007;3:30-38.

Lebrun JJ: The Dual Role of TGF $\beta$ in Human Cancer: From Tumor Suppression to Cancer Metastasis. ISRN Mol Biol 2012:381428.

Massague J: How Cells Read TGF $\beta$ Signals. Nat Rev Mol Cell Biol 2000;1:169-178.

Teng Y, Zhao L, Zhang Y, Chen W, Li X: Id-1, a Protein Repressed by miR-29b, Facilitates the TGFß1-Induced Epithelial- Mesenchymal Transition in Human Ovarian Cancer Cells. Cell Physiol Biochem 2014;33:717730.

Hu Q, Tong S, Zhao X, Ding W, Gou Y, Xu K, Sun C, Xia G: Periostin Mediates TGF- $\beta$-Induced Epithelial Mesenchymal Transition in Prostate Cancer Cells. Cell Physiol Biochem 2015;36:799-809.

Yang J, Weinberg RA: Epithelial-Mesenchymal Transition: At the Crossroads of Development and Tumor Metastasis. Dev Cell 2008;14:818-829.

9 Kalluri R, Weinberg RA: The basics of epithelial-mesenchymal transition. J Clin Invest 2009;119:14201428.

Korc M, Friesel RE. The role of fibroblast growth factors in tumor growth. Curr Cancer Drug Targets 2009;9:639-651. 


\section{Cellular Physiology Cell Physiol Biochem 2017;41:1336-1345 \begin{tabular}{ll|l} 
DOI: 10.1159/000464436 & and Biochemistry Published online: N1Varch 09, 2017 & $\begin{array}{l}\text { O 2017 The Author(s). Published by S. Karger AG, Basel } \\
\text { www.karger.com/cpb }\end{array}$
\end{tabular} \\ Mitra/Roy: TGF $\beta$ and Wnt Together Attenuates EMT}

21 Basu M, Mukhopadhyay S, Chatterjee U, Roy SS: FGF16 promotes invasive behavior of SKOV-3 ovarian cancer cells through activation of mitogen-activated protein kinase (MAPK) signaling pathway. J Biol Chem 2014;289:1415-1428.

-22 Kimelman D, Xu W: beta Catenin destruction complex: insights and questions from a structural perspective. Oncogene 2006;25:7482-7491.

-23 Hedgepeth CM, Conrad LJ, Zhang J, Huang HC, Lee VMY, Klein PS: Activation of the Wnt Signaling Pathway: A Molecular Mechanism for Lithium Action. Dev Biol 1997; 185:82-91.

-24 Rao AS, Kremenevskaja N, Resch J, Brabant G: Lithium stimulates proliferation in cultured thyrocytes by activating Wnt/ $\beta$-catenin signalling. Eur J Endocrinol 2005;153:929-938.

25 Guo X, Wang XF: Signaling cross-talk between TGF- $\beta$ /BMP and other pathways. Cell Res 2009;19:71-88.

26 Fuxe J, Vincent T, Garcia de Herreros A: Transcriptional crosstalk between TGF- $\beta$ and stem cell pathways in tumor cell invasion: Role of EMT promoting Smad complexes. Cell Cycle 2010;9:2363-2374.

27 Zhou S, Eid K, Glowacki J: Cooperation Between TGF- $\beta$ and Wnt Pathways During Chondrocyte and Adipocyte Differentiation of Human Marrow Stromal Cells. J Bone Miner Res 2004;19:463-470.

28 Zhang J, Tian XJ, Xing J: Signal Transduction Pathways of EMT Induced by TGF- $\beta$, SHH, and WNT and Their Crosstalks. J Clin Med 2016;5:41.

29 Basu M, Roy SS: Wnt/ $\beta$-Catenin Pathway Is Regulated by PITX2 Homeodomain Protein and Thus Contributes to the Proliferation of Human Ovarian Adenocarcinoma Cell, SKOV-3. J Biol Chem 2013;288:4355-4367.

-30 Basu M, Bhattacharya R, Ray U, Mukhopadhyay S, Chatterjee U, Roy SS: Invasion of ovarian cancer cells is induced by PITX2-mediated activation of TGF- $\beta$ and Activin-A. Mol Cancer 2015;14:162.

- 31 Bhattacharjee S, Das N, Mandala A, Mukhopadhyay S, Roy SS: Fenofibrate Reverses Palmitate Induced Impairment in Glucose Uptake in Skeletal Muscle Cells by Preventing Cytosolic Ceramide Accumulation. Cell Physiol Biochem 2015;37:1315-1328.

-32 Nandi SS, Ghosh P, Roy SS: Expression of PITX2 Homeodomain Transcription Factor during Rat Gonadal Development in a Sexually Dimorphic Manner. Cell Physiol Biochem 2011;27:159-170.

33 Levy L, Hill CS: Alterations in components of the TGF- $\beta$ superfamily signaling pathways in human cancer. Cytokine Growth Factor Rev 2006;17:41-58.

-34 Son H, Moon A: Epithelial-mesenchymal Transition and Cell Invasion. Toxicol Res 2010;26:245-252.

-35 Wong IY, Javaid S, Wong EA, Perk S, Haber DA, Toner M, Irimia D: Collective and individual migration following the epithelial-mesenchymal transition. Nat Mater 2014;13:1063-1071.

36 Wang Y, Shi J, Chai K, Ying X, Zhou BP: The Role of Snail in EMT and Tumorigenesis. Curr Cancer Drug Targets 2013;13:963-972.

-37 Guaita S, Puig I, Franci C, Garrido M, Domı́nguez D, Batlle E, Sancho E, Dedhar S, De Herreros AG, Baulida J: Snail Induction of Epithelial to Mesenchymal Transition in Tumor Cells Is Accompanied by MUC1 Repression and ZEB1 Expression. J Biol Chem 2002;277:39209-39216.

- 38 Michalik M, W’ojcik KA, Jakieła B, Szpak K, Pierzchalska M, Sanak M, Madeja Z, Czy'z J: Lithium Attenuates TGF- $\beta 1$-Induced Fibroblasts to Myofibroblasts Transition in Bronchial Fibroblasts Derived from Asthmatic Patients. J Allergy (Cairo) 2012;2012:206109.

- 39 Sun Q, Guo S, Wang CC, Sun X, Wang D, Xu N, Jin SF, Li KZ: Cross-talk between TGF- $\beta$ /Smad pathway and Wnt/ $\beta$-catenin pathway in pathological scar formation. Int J Clin Exp Pathol 2015;8:7631-7639.

-40 Beldowski M: Assessment of plasma $\beta$-catenin concentration as biomarker of thyroid cancer. Pol Przegl Chir 2015;87:340-345. 